\title{
Molecular Simulation of Adsorption: Gibbs Dividing Surface and Comparison With Experiment
}

Orhan Talu

Cleveland State University

Alan L. Myers

University of Pennsylvania

Follow this and additional works at: https://engagedscholarship.csuohio.edu/encbe_facpub

Part of the Thermodynamics Commons, and the Transport Phenomena Commons

How does access to this work benefit you? Let us know!

\section{Publisher's Statement}

This is the accepted version of the following article: Talu, O., \& Myers, A. L. (2001). Molecular simulation of adsorption: Gibbs dividing surface and comparison with experiment. AIChE Journal, 47(5), 1160 - 1168. doi:10.1002/aic.690470521, which has been published in final form at http://onlinelibrary.wiley.com/doi/10.1002/aic.690470521/abstract

\section{Original Citation}

Talu, O., \& Myers, A. L. (2001). Molecular simulation of adsorption: Gibbs dividing surface and comparison with experiment. AIChE Journal, 47(5), 1160 - 1168. doi:10.1002/aic.690470521

\section{Repository Citation}

Talu, Orhan and Myers, Alan L., "Molecular Simulation of Adsorption: Gibbs Dividing Surface and Comparison With Experiment" (2001). Chemical \& Biomedical Engineering Faculty Publications. 43.

https://engagedscholarship.csuohio.edu/encbe_facpub/43

This Article is brought to you for free and open access by the Chemical \& Biomedical Engineering Department at EngagedScholarship@CSU. It has been accepted for inclusion in Chemical \& Biomedical Engineering Faculty Publications by an authorized administrator of EngagedScholarship@CSU. For more information, please contact library.es@csuohio.edu. 


\title{
Molecular Simulation of Adsorption: Gibbs Dividing Surface and Comparison with Experiment
}

\author{
Orhan Talu \\ D ept. of Chemical E ngineering, Cleveland State U niversity, Cleveland, O H 44115 \\ Alan L. M yers \\ Dept. of Chemical Engineering, U niversity of Pennsylvania, Philadelphia, PA 19104
}

\begin{abstract}
At low temperature near the normal boiling point, computer simulations of adsorption of gases can be compared directly with experiment. However, for adsorptive gas separations in which the gas is adsorbed near or above its critical temperature, absolute simulation variables must be converted to excess variables for comparison with experiment. The conversion of absolute to excess $v$ ariables requires the helium pore $v$ olume of the adsorbent. L ennard-J ones potential parameters for helium gas molecules interacting with the oxygen atoms of silicalite are $\epsilon / \mathrm{k}=28.0 \mathrm{~K}$ and $\sigma=2.952 \mathrm{~A}$. The helium pore $v$ olume of silicalite is $0.175 \mathrm{~cm}^{3} / \mathrm{g}$. L ennard-J ones potential parameters derived for A $\mathrm{r}-\mathrm{O}$ interactions in silicalite are $\epsilon / \mathrm{K}=93.0 \mathrm{~K}$ and $\sigma=3.335 \mathrm{~A}$. Density profiles for adsorption of argon in silicalite at $300 \mathrm{~K}$ show that the local density is highest in the middle of the channels where the gas-solid potentials overlap.
\end{abstract}

\section{Introduction}

\section{Adsorption experiments}

Although the terminology "adsorbed phase" is used freely, the thermodynamics of molecules adsorbed in porous solids differs from the thermodynamics of bulk fluids and requires special treatment. Bulk fluid phases are homogeneous and isotropic on a macroscopic scale, but the properties of an adsorbed phase (density, energy, and so on) are a strong function of position even at equilibrium. Physical forces of attraction exerted by the solid atoms cause the gas density to increase in a narrow layer adjacent to the surface of the solid. How close to the surface must a molecule be in order to be classified as adsorbed? The ambiguity inherent in this question was famously avoided (Gibbs, 1961) by defining the adsorbed phase as the actual amount of gas present minus the amount of gas that would be present in the same space at the prevailing bulk density of the gas. The specific G ibbs excess adsorption $\mathrm{N}^{\mathrm{m}}$ is determined experimentally by (Sircar, 1985)

$$
\mathrm{N}^{\mathrm{m}}=\mathrm{N}^{\mathrm{a}}-\mathrm{V}_{\mathrm{d}} \rho_{\mathrm{b}}
$$

The superscript $\mathrm{m}$ means measured by experiment. $\mathrm{N}^{\mathrm{a}}$ is the total number of molecules introduced to the sample cell per unit mass of adsorbent, $V_{d}$ is the specific dead space of the apparatus ( $\mathrm{cm}^{3}$ per unit mass of adsorbent), and $\rho_{\mathrm{b}}$ is the density of the equilibrium gas phase determined by independent measurements of its equation of state. At sufficiently low pressure, the equation of state is the ideal gas law

$$
\rho_{\mathrm{b}}=\frac{\mathrm{P}}{\mathrm{kT}}
$$

The statistical thermodynamics notation of number of molecules $(\mathrm{N})$ and Boltzmann constant $(\mathrm{k})$ is used throughout this article; conversion to moles $\left(\mathrm{N} / \mathrm{N}_{\text {avo }}\right.$ ) or the gas constant $\left(\mathrm{R}=\mathrm{kN}_{\mathrm{avo}}\right)$ is made with A vogadro's number $\left(\mathrm{N}_{\mathrm{avo}}\right)$.

B efore starting adsorption experiments, the dead space $V_{d}$ is determined with helium gas at ambient temperature $\left(T_{0}\right)$ and low pressure 


$$
\mathrm{V}_{\mathrm{d}}=\frac{\mathrm{N}^{\mathrm{a}} \mathrm{kT}}{\mathrm{P}} \quad \text { (for helium) }
$$

where $\mathrm{N}^{\text {a }}$ is the total amount of helium introduced to the sample cell containing the adsorbent. The measurement of dead space by Eq. 3 is based upon the reasonable assumption that adsorption of helium at room temperature can be neglected.

The above considerations are independent of the measurement technique and apply to the gravimetric, as well as the volumetric, method. The volumetric technique depends upon helium expansion experiments to measure the dead space or so-called void volume in the sample chamber; the gravimetric method requires the helium density to determine the solid volume for the calculation of the buoyancy force (Talu, 1998). In essence, helium is used in both techniques to establish the location of the Gibbs dividing surface.

\section{Comparing Simulated Adsorption Isotherms with Experiment}

Molecular simulation of adsorption in microporous adsorbents is performed on a representative sample of the solid, which for a zeolite is several unit cells with periodic boundary conditions. A dsorption on the external surface of the solid is usually ignored and Eq. 1 may be written

$$
\mathrm{N}^{\mathrm{m}}=\mathrm{N}^{\mathrm{a}}-\mathrm{V}_{\mathrm{p}} \rho_{\mathrm{b}}
$$

where $V_{p}$ is the specific pore volume $\left(\mathrm{cm}^{3} / \mathrm{g}\right)$ of the adsorbent. The quantity $\mathrm{N}^{\mathrm{a}}$ in $\mathrm{Eq} .4$, called absolute adsorption, is the total number of molecules contained in the pores (micropores or mesopores) per unit mass of solid material.

Determination of the pore volume by simulation must mimic the experiment. Since the experimental determination of dead space assumes that helium is a nonadsorbing gas $\left(\mathrm{N}^{\mathrm{m}}=0\right)$, it follows from $\mathrm{Eq} .4$ that

$$
\mathrm{V}_{\mathrm{p}}=\frac{\mathrm{N}^{\mathrm{a}}}{\rho_{\mathrm{b}}} \quad \text { (for helium) }
$$

At low pressure

$$
V_{p}=\frac{N^{a} k T_{0}}{P} \quad \text { (for helium) }
$$

which is the same as Eq. 3 except that $\mathrm{N}^{\text {a }}$ now refers to the total number of helium molecules contained in the simulation box per unit mass of adsorbent.

\section{Pore volume from adsorption second $v$ irial coefficients}

Instead of simulating helium in pores, it is more convenient to calculate the pore volume from the adsorption second virial coefficient (B). The adsorption second virial coefficient from experiment is

$$
B^{m}=k T \lim _{P \rightarrow 0}\left(\frac{d N^{m}}{d P}\right)
$$

and the adsorption second virial coefficient from simulation is

$$
B^{a}=k T \lim _{P \rightarrow 0}\left(\frac{d N^{a}}{d P}\right)
$$

Combination of Eqs. 4, 7, and 8 gives

$$
B^{m}=B^{a}-V_{p}
$$

For helium, both $\mathrm{N}^{\mathrm{m}}$ and $\mathrm{B}^{\mathrm{m}}$ are zero so

$$
V_{p}=B^{a} \quad\left(\text { for helium at } T_{0}\right)
$$

The absolute adsorption second virial coefficient in $\mathrm{cm}^{3} / \mathrm{g}$ is given by the configuration integral

$$
\mathrm{B}^{\mathrm{a}}=\frac{1}{\mathrm{~m}_{\mathrm{s}}} \int \mathrm{e}^{-\phi(\mathbf{r}) / \mathrm{kT}} \mathrm{d} \mathbf{r}
$$

where $m_{s}$ is the mass of a representative sample of solid adsorbent in the simulation and $\phi$ is the gas-solid potential energy of a single molecule. Integration is over the entire sample. The exponential is finite inside the pores but vanishes within the solid where $\phi \rightarrow \infty$.

The adsorption second virial coefficient refers to the limit of zero pressure, while actual experiments with helium are conducted at finite pressure. Is there a measurable adsorption of helium at finite pressure? Experiments that are based on the assumption that helium does not adsorb cannot answer this question. However, simulations can provide an answer by comparing the average pore density.

$$
\rho_{\mathrm{p}}=\frac{\mathrm{N}^{\mathrm{a}}}{\mathrm{V}_{\mathrm{p}}}
$$

with the equilibrium gas density $\rho_{\mathrm{b}}$. E quality of the two densities would satisfy the hypothesis that the excess adsorption of helium is zero. This comparison will be made later.

Thie integral in Eq. 11 indicates that the helium pore volume is a function of temperature. However, the variation of the integral with temperature is weak: raising the temperature from 300 to $1,000 \mathrm{~K}$ increases the value of the integral by only $2.6 \%$. A lthough the integral is insensitive to temperature, in principle the simulation should be performed at the temperature used for the experimental determination of helium pore volume.

In summary, the key equations for converting absolute adsorption $\left(\mathrm{N}^{\mathrm{a}}\right.$ ) from simulations to excess adsorption $\left(\mathrm{N}^{\mathrm{m}}\right.$ ) for comparison with experiment are Eqs. 4 and 10.

\section{Comparing Simulations of Isosteric Heat with Experiment}

Simulations of adsorption yield the gas-gas and gas-solid potential energy; adsorption experiments yield the isosteric heat, which is a differential enthalpy. In this section, it is shown how the differential enthalpy of experiment may be compared with the simulated potential energy. 
The usual definition of the isosteric heat of adsorption is

$$
q_{s t}=k T^{2}\left(\frac{\partial \ln P}{\partial T}\right)_{N m}
$$

The heat of adsorption measured experimentally depends upon the imposed conditions: batch, steady state, isothermal, isobaric, and so on. The existence of several different types of heats of adsorption (equilibrium, integral, differential, isosteric) adds to the confusion. Instead of insisting upon a particular path for the definition of isosteric heat, it is advantageous to work with differential and integral enthalpies which are state variables and, therefore, independent of the path. The integral enthalpy of desorption to the perfect gas state is

$$
\Delta H^{m}=h^{*} N^{m}-H^{m}
$$

Stated differently, $-\Delta H^{m}$ is the integral enthalpy of the adsorbed phase relative to the perfect-gas reference state. $\mathrm{H}^{\mathrm{m}}$ is specific enthalpy per unit mass of adsorbent. The differential enthalpy of desorption is

$$
\Delta \bar{h}^{m}=\left[\frac{\partial \Delta \mathrm{H}^{\mathrm{m}}}{\partial \mathrm{N}^{\mathrm{m}}}\right]_{\mathrm{T}}=\mathrm{h}^{*}-\left[\frac{\partial \mathrm{H}^{\mathrm{m}}}{\partial \mathrm{N}^{\mathrm{m}}}\right]_{\mathrm{T}}
$$

The differential enthalpy of desorption may be measured directly by calorimetry (D unne et al., 1996) or indirectly from adsorption isotherms by the rigorous thermodynamic equation (Siperstein and M yers, 2000)

$$
\Delta \bar{h}^{m}=k T^{2}\left[\frac{\partial \ln f}{\partial T}\right]_{N}
$$

For a perfect gas, the fugacity ( $\mathrm{f}$ ) is equal to the pressure

$$
\Delta \bar{h}^{\mathrm{m}}=\mathrm{k} \mathrm{T}^{2}\left[\frac{\partial \ln \mathrm{P}}{\partial \mathrm{T}}\right]_{\mathrm{N}^{\mathrm{m}}}
$$

Comparison of Eqs. 13 and 17 shows that the differential enthalpy of desorption is equal to the isosteric heat for the special case of a pure perfect gas, but Eq. 16 provides a more general thermodynamic connection between calorimetry and adsorption isotherms.

The absolute differential enthalpy of desorption can be calculated (Nicholson and Parsonage, 1977) from fluctuations in absolute adsorption ( $\mathrm{N}^{\mathrm{a}}$ ) and potential energy $(\phi)$

$$
\Delta \bar{h}^{a}=-\frac{f\left(\phi, N^{a}\right)}{f\left(N^{a}, N^{a}\right)}+k T
$$

where $f(X, Y)=\langle X Y\rangle-\langle X\rangle\langle Y\rangle$ refers to the co-variance of $X-Y$ pairs.

For finite loading, we are unaware of any straightforward relationship between absolute differential enthalpy from simulation $\left(\Delta \bar{h}^{\mathrm{a}}\right)$ and differential enthalpy (isosteric heat) from experiment $\left(\Delta \bar{h}^{\mathrm{m}}\right)$. Comparisons at finite loading will be the subject of a future article. A useful relationship for the limit of zero pressure is (M yers et al., 1997)

$$
\Delta \bar{h}^{m}=\frac{\Delta \bar{h}^{a}}{1-\frac{V_{p}}{B^{a}}} \quad(\text { at } \mathrm{P}=0)
$$

Equation 19 shows that the experimental differential enthalpy of desorption $\left(\Delta \bar{h}^{m}\right)$ is larger than the absolute differential enthalpy $\left(\Delta \bar{h}^{a}\right)$ from simulations.

Applying Eq. 17 to the limiting form of the adsorption isotherm in E q. 7 while expressing the adsorption second virial coefficient as an integral according to Eqs. 9 and 11 yields the following expression for the differential enthalpy of desorption (isosteric heat) at the limit of zero pressure

$$
\Delta \bar{h}^{m}=-\frac{\int \phi(\mathbf{r}) \mathrm{e}^{-\phi(\mathbf{r}) / k T} d \mathbf{r}}{\int \mathrm{e}^{-\phi(\mathbf{r}) / k T} d \mathbf{r}-\mathrm{m}_{\mathrm{s}} \mathrm{V}_{\mathrm{p}}}+\mathrm{kT} \quad(\text { at } \mathrm{P}=0)
$$

where $\phi$ is the gas-solid potential energy function for a single molecule and the integrations are performed over a representative mass $\left(m_{s}\right)$ of solid adsorbent.

Combining Eqs. 9 and 11

$$
B^{m}=\frac{1}{m_{s}} \int e^{-\phi(r) / k T} d \mathbf{r}-V_{p}
$$

E quations 20 and 21 will be solved for two unknown potential parameters, given experimental values for the $\mathrm{H}$ enry constant $\left(B^{m} / k T\right)$ and limiting isosteric heat $\left(\Delta \bar{h}^{m}\right)$.

\section{Potential Function}

Molecular simulations were first performed shortly after the invention of the computer (M etropolis et al., 1953); simulation of adsorption came later (Stroud et al., 1976; Nicholson and Parsonage, 1977; Soto and M yers, 1981). The numerical techniques, as well as the statistical equations that relate the simulation data to thermodynamic properties, are well established. The weakest link in molecular simulation is the potential function.

On the one hand, the sound theoretical approach of performing $a b$ initio calculations of intermolecular energies is computationally intractable for adsorption systems containing a dense adsorbed phase inside a nano-scale structured solid. On the other hand, the inability to obtain accurate intermolecular energies from theory does not hinder the development of molecular simulation as an engineering tool. At present, the state of the art is to use effective functions such as the Lennard-J ones potential for dispersion. Induction energy (such as dipole-induced dipole) is sometimes neglected and therefore lumped implicitly with dispersion energy. E lectrostatic energies are calculated either from Coulomb's law or multipole expansions of charge distributions. This approach has already yielded great advances in the understanding of bulk-fluid equilibrium and transport properties. M olecular simulation of adsorption is an order of magnitude more 
complicated because of the need to model the structure of the solid on an atomic scale, but the introduction of effective potential functions makes the task feasible on a desktop computer.

The use of effective potential functions presupposes knowledge of the parameters in these functions. Several attempts have been made to calculate these parameters from molecular properties such as polarizability amd diamagnetic susceptibility using London or K irkwood-M üller theories of dispersion, but the results have been disappointing (Talu, 1991). A s a result, values of effective parameters are usually extracted from experimental data.

The use of adsorption data to extract effective parameters, which are used in turn to simulate adsorption and compare the results with experiment, may seem like a self-fulfilling endeavor, especially for single-gas adsorption. N evertheless, this approach will be necessary for the foreseeable future. O ne strength of molecular simulation is its ability to provide guidance in optimizing the properties of materials by taking snapshots of dynamic and equilibrium behavior. The greatest potential for molecular simulation lies in the accurate prediction of multicomponent behavior from data for single gases.

It is highly desirable to generate a table of effective potential parameters for gas-solid pairs similar to tables generated previously for simple molecules such as $\mathrm{Ar}$ and $\mathrm{CO}_{2}(\mathrm{H}$ irschfelder et al., 1954). Previous sets of potential parameters were derived from experimental data such as second virial coefficients of gases. A worthwhile long-term goal is to create such a table for gas-solid interactions between simple molecules and various solids of practical importance. As a first step, we chose to work with silicalite, which is the pure silica form of ZSM -5 and contains a three-dimensional pore structure of straight and sinusoidal shaped intersecting pores with a diameter of about $5.7 \AA$. The structure is well known (Olson et al., 1981) and ample experimental data for adsorption of gases are available in the literature.

The absence of exchangeable cations in the silicalite structure circumvents complications introduced by strong electrical fields in the pore space. Since the objective is to determine effective gas-solid potential parameters, all induced electrostatic interactions caused by the charges on silicon and oxygen atoms are lumped into a single effective potential function. The pairwise energy between guest molecules and oxygen atoms in silicalite is approximated with the LennardJones potential

$$
\phi_{i j}=4 \epsilon_{i j}\left[\left(\frac{\sigma_{i j}}{r}\right)^{12}-\left(\frac{\sigma_{i j}}{r}\right)^{6}\right]
$$

A pre-tabulation scheme was utilized to calculate gas-solid potentials using crystallographic data (Olson et al., 1981) and a $0.1 \AA$ 3-D grid. The cut-off radius of $100 \AA$ used for the pre-tabulation contained about 30,000 oxygen atoms in the solid. A lthough the pre-tabulation is itself time-consuming, it needs to be done only once if the potentials are summed in dimensionless form. For the simulation, the pre-tabulated energy was interpolated linearly to calculate the gas-solid interaction corresponding to a given location. The calculation of the adsorption second virial coefficient by Eq. 21 and the zero-pressure differential enthalpy by Eq. 20 was reduced to a summation over the pre-tabulation, which is very efficient compared to a M onte Carlo integration. This computational efficiency enabled the zero-pressure calculations to be included in an optimization routine for the extraction of potential parameters as explained later.

In the grand canonical M onte Carlo (G CMC) simulations described below, the gas-gas interactions were also represented by $\mathrm{Eq} .22$ with parameters taken from the literature (H irschfelder et al., 1954).

\section{Determination of Gas-Solid Potentials}

The potential parameters for helium-oxygen interactions are needed for the calculation of the pore volume by E qs. 10 and 11. Figure 1 shows the effect of helium-oxygen parameters on the calculated pore volume. Obviously, an infinite number of combinations of $\epsilon_{\mathrm{ij}}$ and $\sigma_{\mathrm{ij}}$ parameters gives the same pore volume (which at this point is unknown). In order to resolve the pore volume while obtaining effective potential parameters for gas-solid interactions, we used experimental data for adsorption of argon and invoked Lorentz-Berthelot mixing rules

$$
\begin{gathered}
\epsilon_{\mathrm{ij}}=\left(\epsilon_{\mathrm{ii}} \epsilon_{\mathrm{jj}}\right)^{0.5} \\
\sigma_{\mathrm{ij}}=\frac{\sigma_{\mathrm{ii}}+\sigma_{\mathrm{jj}}}{2}
\end{gathered}
$$

The gas-solid potential constants in Table 1 were derived from experimental data (D unne et al., 1996; Golden and Sircar, 1994) for adsorption of argon on silicalite at $32.6^{\circ} \mathrm{C}: \mathrm{B}^{\mathrm{m}}=4.35$ $\mathrm{cm}^{3} / \mathrm{g}$ and $\quad \bar{h}^{\mathrm{m}}=15.7 \mathrm{~kJ} / \mathrm{mol} . \quad \bar{h}^{\mathrm{m}}$ and $B^{\mathrm{m}}$ were calculated from Eqs. 20 and 21; the helium pore volume was obtained from E qs. 10 and 11. A steepest-descent optimization routine

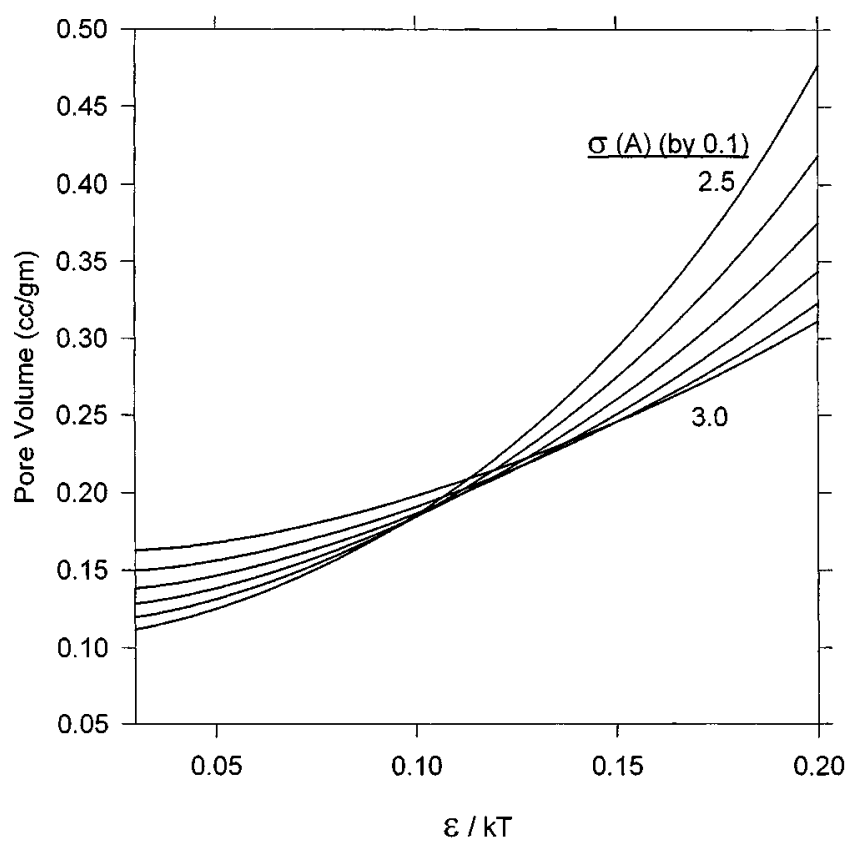

Figure 1. Pore volume in silicalite as a function of He-O potential parameters ( $\epsilon$ and $\sigma$ ) at $300 \mathrm{~K}$. 
Table 1. Lennard-J ones 12-6 Potential Parameters for Adsorption in Silicalite

\begin{tabular}{crrl}
\hline A tom pair & $\epsilon / \mathrm{k}(\mathrm{K})$ & $\sigma,(\AA)$ & \multicolumn{1}{c}{ R ef. } \\
\hline H e-H e & 10.9 & 2.640 & (H irschfelder et al., 1954) \\
A r-A r & 119.8 & 3.405 & ibid. \\
O -O & 72.2 & 3.265 & This study \\
He-O & 28.0 & 2.952 & E qs. 23-24 \\
A r-O & 93.0 & 3.335 & E qs. 23-24 \\
\hline
\end{tabular}

was used to extract the potential parameters in Table 1 . The two unknowns extracted from the optimization, the oxygenoxygen potential parameters ( $\sigma$ and $\epsilon$ ), have no physical meaning beyond their use in Eqs. 23 and 24. Nevertheless, these constants are essential for the development of a table of effective potential parameters as discussed previously. The $\mathrm{He}-\mathrm{O}$ potential parameters in Table 1 are also needed for the determination of pore volume $\left(\mathrm{V}_{\mathrm{p}}\right)$; the value calculated for silicalite from Eqs. 10 and 11 is $0.175 \mathrm{~cm}^{3} / \mathrm{g}$.

O ur values for the oxygen-oxygen potential parameters in Table 1 disagree with values of $\epsilon / \mathrm{k}=89.6 \mathrm{~K}$ and $\sigma=2.81 \AA$ obtained by $\mathrm{H}$ euchel et al. (1997), and values of $\epsilon / \mathrm{k}=55.71$ $\mathrm{K}$ and $\sigma=3.658$ A obtained by Smit (1995). Both articles concentrated on adsorption of methane in silicalite without converting absolute variables to experimental excess variables.

Figure 2 shows the contours in parameter space for the experimental value of the adsorption second virial coefficient and limiting differential enthalpy for A $r$ in silicalite. The optimal solution is located at the intersection of the experimen-

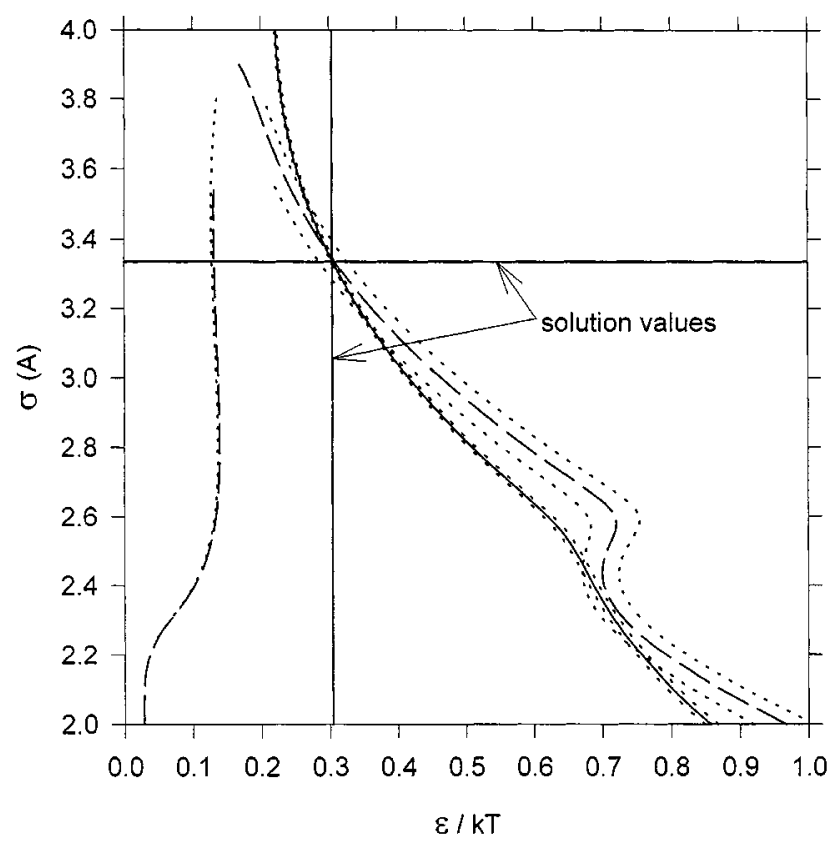

Figure 2. Loci of adsorption second virial coefficient (solid line) and differential enthalpy (dashed line) in parameter space for $B=4.35 \mathrm{~cm}^{3} / \mathrm{g}$ and $\Delta \overline{\mathbf{h}}^{\mathbf{m}}=\mathbf{1 5 . 7} \mathrm{kJ} / \mathrm{mol}$ at $\mathrm{T}=305.75 \mathrm{~K}$.

Dotted lines delineate $\pm 5 \%$ error bars. The solution lies at the intersection of the two loci.

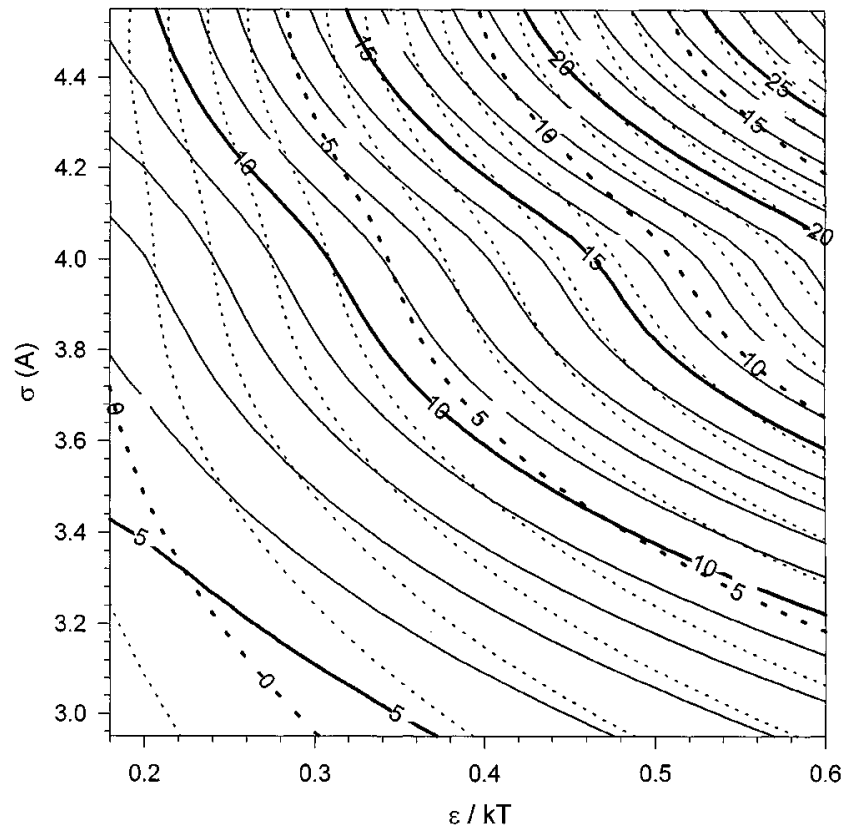

Figure 3. Extracting gas-solid potential parameters from experimental data for spherical molecules adsorbed in silicalite.

Solid lines are loci for the dimensionless differential enthalpy $\left(\bar{h}^{m} / k T\right)$. D ashed lines are loci for the logarithm of the second virial coefficient $\left(\ln B^{m}\right)$ with $B^{m}$ in units of $\mathrm{cm}^{3} / \mathrm{g}$. The solution lies at the intersection of the two loci.

tal loci $(\epsilon / \mathrm{kT}=0.304$ and $\sigma=3.335 \AA)$. There are several interesting features on Figure 2. First, a series of solutions for differential enthalpy exists at unrealistically low values of $\epsilon$ where the argon molecule is very close to the impenetrable solid space. As $\epsilon$ approaches zero, the molecule does not "see" the wall regardless of its size. Second, the two contours come close to an intersection at $\epsilon / \mathrm{kT}=0.71$ and $\sigma=2.3 \mathrm{~A}$. Although this point is not an optimum for the experimental data, it is well within the $5 \%$ uncertainty envelope shown. Third, at the physically realistic solution, the contours of the $\mathrm{H}$ enry constant and differential enthalpy are almost parallel so that the optimal values are very sensitive to errors in the experimental data, particularly errors in the differential enthalpy. Figure 2 shows that only experimental data of extraordinary precision are capable of yielding accurate values of well depth and collision diameter for the gas-solid potential. In most circumstances. additional information such as experimental data at finite loading is needed for the robust determination of gas-solid potentials.

Contours similar to those in Figure 2 were calculated by Smit (1995) for methane, ethane, and propane adsorption in silicalite. Locating an optimum set of parameters was difficult because the loci were almost parallel.. A bsolute simulation variables were not converted to excess variables for linkage with experiment.

A contour map similar to Figure 2 was generated on Figure 3 for a range of experimental values of adsorption second virial coefficients and limiting enthalpies. Corrections were made for the pore volume of silicalite in E qs. 20 and 21. The solution for gas-solid Lennard-J ones 12-6 potential parame- 


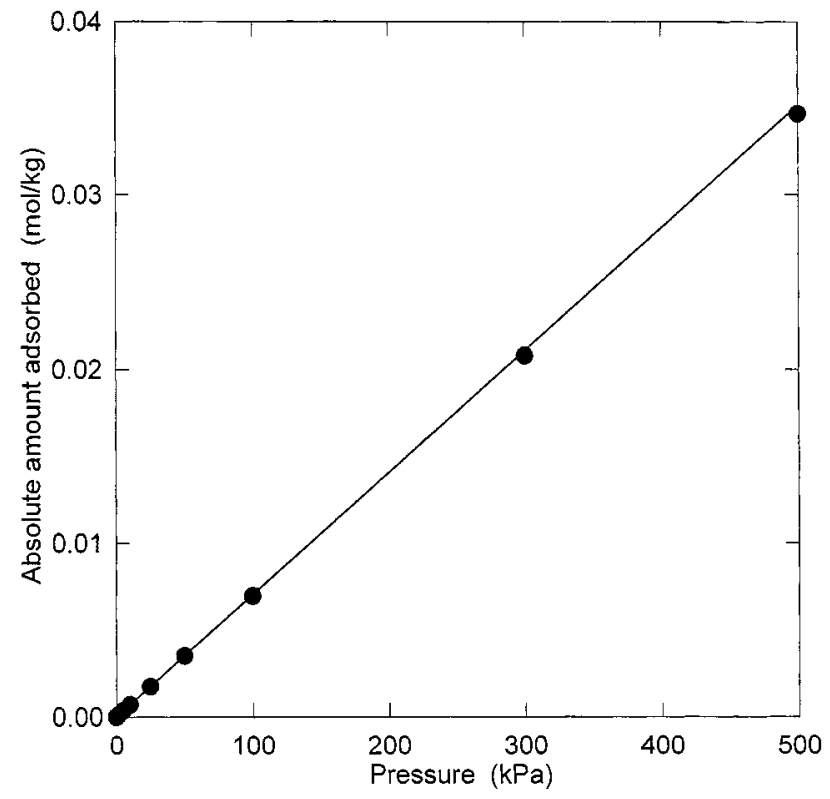

Figure 4. Absolute adsorption of helium on silicalite at $300 \mathrm{~K}$ from GCMC simulations and Henry's law.

- GCM C simulations; solid line: Henry's law from Eqs. 8 and 11 . He-O potential parameters from Table 1.

ters can be found at the intersection of the contour lines, given experimental values for the adsorption second virial coefficient $\left(B^{m}\right)$ and limiting differential enthalpy $\left(\bar{h}^{m}\right)$. A gain, it is emphasized that very accurate data are needed to resolve the potential parameters since the contour lines are nearly parallel.

\section{Simulations of Absolute Adsorption of Helium in Silicalite}

A II experimental adsorption data are based on helium as a nonadsorbing reference gas. As discussed previously, it is impossible to determine experimentally if helium adsorbs without making assumptions about the extent of the interfacial region. Nevertheless, several groups (Springer et al., 1969; Suzuki et al., 1987; Sircar, 2000) have measured the absolute adsorption of helium based on various assumptions. G CM C simulations (see next section for details) of the absolute adsorption of helium based on the potential parameters in Table 1 are plotted on Figure 4 and compared with the Henry's law prediction from Eq. 7. The agreement merely confirms that absolute helium adsorption obeys $\mathrm{H}$ enry's law up to $500 \mathrm{kPa}$.

In order to test the assumption that helium does not adsorb, the GCMC simulations were converted to pore density using $\mathrm{Eq}$. 12. The ratio of the pore density to the bulk density $(\mathrm{P} / \mathrm{kT})$ is plotted on Figure 5 . A scatter of about $1 \%$ in the data at sub-atmospheric pressure is due to a loss of accuracy in G CM C simulations as density approaches zero. A ratio of unity would be expected for pores of macroscopic size. The average value of about 0.99 may be an artifact of the fuzziness of the bulk density concept in a micropore. If helium were adsorbing, the density ratio would be greater than unity and would increase with pressure. In fact, the pore density is

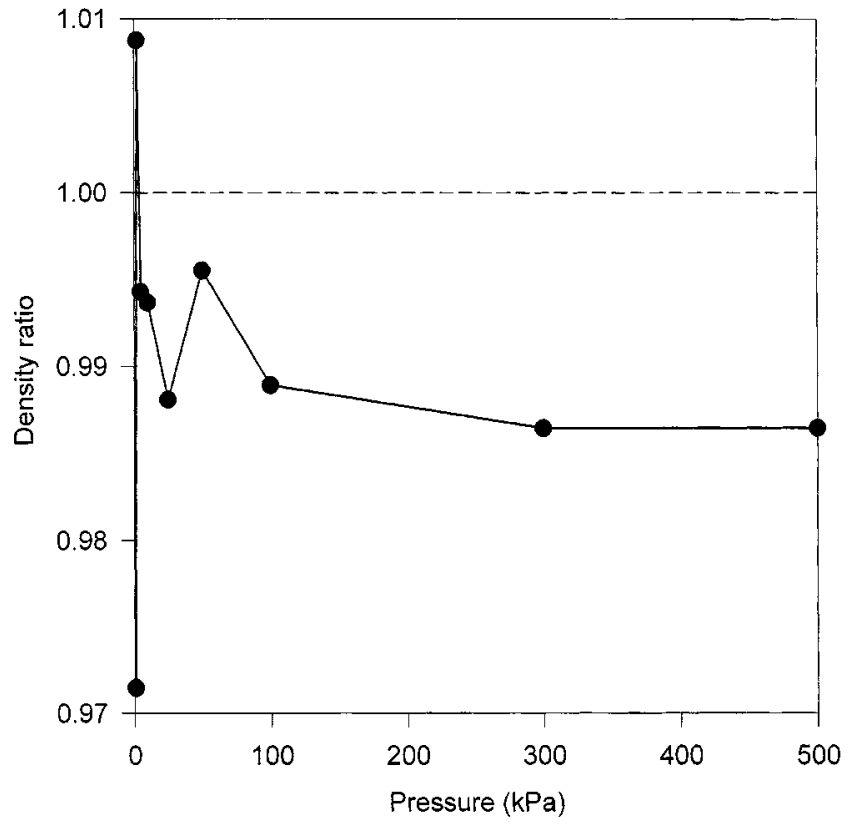

Figure 5. Ratio of absolute density of helium in pores of silic alite $\left(N a / V_{p}\right)$ to bulk density $(P / k T)$ at 300 K.

Nonadsorption of helium corresponds to density ratio of unity. He-O potential parameters from Table 1 .

equal to the bulk density (within 1\%) and the use of helium at room temperature as a nonadsorbing reference gas seems to be fully justified.

\section{Simulations of Adsorption in Argon in Silicalite}

The GCMC simulations were run to convergence, as defined by reduction of the standard deviation in $\phi$ and $\mathrm{N}^{\mathrm{a}}$ to $1-5 \%$. The number of cycles required for convergence varied from 0.5 to 50 million. Longer runs were necessary when the density of guest molecules were either low (helium simulations at low pressure) or high (argon simulations at high pressure). The simulation box was 12 unit cells of silicalite, which is approximately $40 \AA$ on a side and provides periodic boundary conditions. A s explained previously, the cut-off radius for the pretabulated gas-solid energy was $100 \AA$. The cut-off radius for the gas-gas interactions was set at $20 \AA$.

Comparisons of absolute adsorption $\left(\mathrm{N}^{\mathrm{a}}\right.$ ) with excess adsorption $\left(\mathrm{N}^{\mathrm{m}}\right.$ ) calculated from $\mathrm{Eq} .1$ are shown in Figure 6 for argon. The log-log plot obscures the fact that the absolute adsorption at $69.4^{\circ} \mathrm{C}$ is about $10 \%$ higher than the excess adsorption. This $10 \%$ difference persists down to the lowest measured pressure.

The simulations are compared with experiment (D unne et al., 1996; Golden and Sircar, 1994) on Figure 7. The maximum error, which occurs at high loading, is about $5 \%$. Incidentally, at the highest pressure $(800 \mathrm{kPa})$ and lowest temperature $\left(32.6^{\circ} \mathrm{C}\right)$ of this study, the compressibility factor of argon differs from unity by less than $1 \%$ so calculations of bulk density were based upon perfect gas behavior.

The experimental value of the differential enthalpy (isosteric heat) is $15.7 \pm 0.5 \mathrm{~kJ} / \mathrm{mol}$ at low loading. However, the 


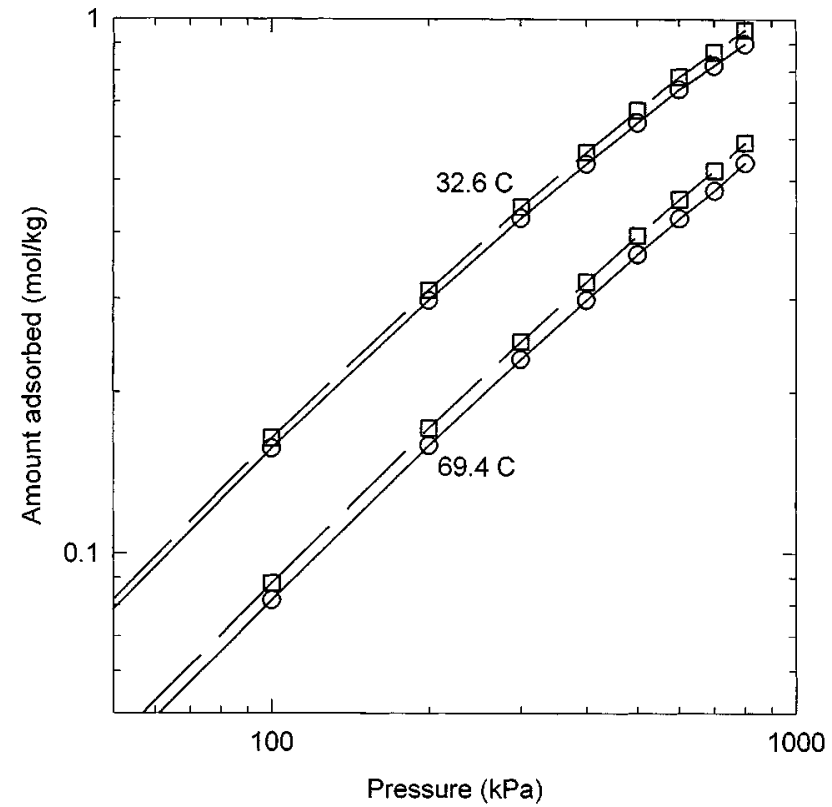

Figure 6. Comparison of absolute and excess adsorption obtained from GCMC simulations of adsorption of argon in silicalite at 32.6 and $69.4^{\circ} \mathrm{C}$.

$\square$ : absolute adsorption $\left(\mathrm{N}^{\mathrm{a}}\right)$; $\mathrm{O}$ : excess adsorption $\left(\mathrm{N}^{\mathrm{m}}\right)$ A r-A r and Ar-O potential parameters from Table 1 .

probable error of the mean $(15.7 \mathrm{~kJ} / \mathrm{mol})$ is less than 0.1 $\mathrm{kJ} / \mathrm{mol}$ because of the large number (21) of experimental points. The small error $(<1 \%)$ in the limiting value of en-

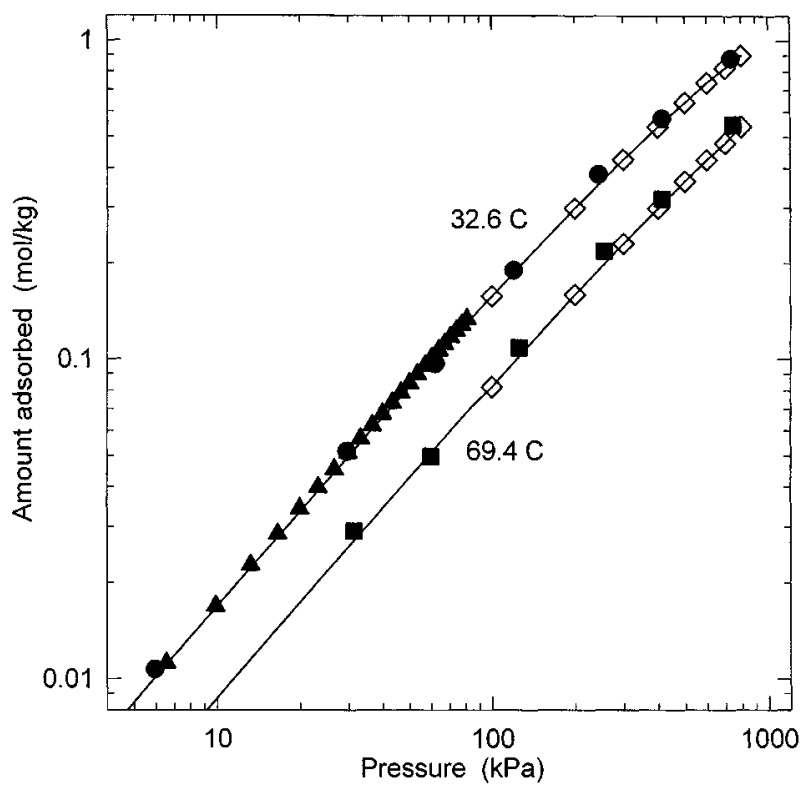

Figure 7. Comparison of simulation with experiment for adsorption of argon in silicalite.

$\diamond: \mathrm{N}^{\text {a }}$ from simulations; $\boldsymbol{\Delta}: \mathrm{N}^{\mathrm{m}}$ at $32.6^{\circ} \mathrm{C}$ (D unne et al. (1996); $\mathrm{O} \mathrm{N}^{\mathrm{m}}$ at $32.6^{\circ} \mathrm{C}$ (Golden and Sircar, 1994); $\mathbf{a}: \mathrm{N}^{\mathrm{m}}$ at $69.4^{\circ} \mathrm{C}$ (G olden and Sircar, 1994). A r-A r and A r-O potential parameters from Table 1. thalpy made possible the accurate determination of potential parameters on Figure 2. A s explained previously, Eq. 20 with the A r-O potential parameters in Table 1 reproduces the experimental differential enthalpy $(15.7 \mathrm{~kJ} / \mathrm{mol})$.

\section{Density Profiles for Helium and Argon in Pores of Silicalite}

Simulations provide detailed information about the behavior of gas molecules in the pore space ( $\mathrm{Li}$ and Talu, 1993). Figure 8 shows profiles for the average number of molecules $\left\langle\mathrm{N}^{\mathrm{a}}\right\rangle$ in the two channels of silicalite. The pores in silicalite are illustrated in M eier and O Ison (1992); the straight pores of the main channel intersect at nearly right angles with the zig-zag pores of the side channel. Both pores are nearly cylindrical in shape with diameters in the range from 5.1 to $5.6 \mathrm{~A}$. The length of the main and side channels between intersections is about $5 \AA$. The periodicity of the main channel ( $y$ direction) is about $5 \AA$, but the periodicity of the sinusoidal side channel ( $x$ direction) is about $10 \AA$ because of its zig-zag shape. The largest values of $\left\langle\mathrm{N}^{\mathrm{a}}\right\rangle$ are located at the channel intersections. Although the intersections do not have the highest potential, the larger volume of the interaction results in higher values of $\left\langle\mathrm{N}^{\mathrm{a}}\right\rangle$. The occupation for helium is much lower than for argon in line with the interaction potentials.

The occupation profiles can be converted to local density profiles using the local pore volume at each cross section. The latter was calculated from E qs. 10 and 11 by integration over each cross section. Local density profiles calculated this way are shown on Figure 9. The local helium density profile is flat within the statistical accuracy of the GCMC simulations, and the value is approximately equal to the bulk gas density, as discussed previously. Thus, helium does not adsorb under these conditions. A rgon density is about one order of magnitude higher than helium density throughout the pore space. The highest density for argon occurs near the middle of the channels where the gas-solid potential is highest (in absolute terms) due to potential overlap. The intersections can accommodate more molecules as indicated by the $\left\langle\mathrm{N}^{\mathrm{a}}\right\rangle$ profiles, but the density is lower due to the smaller absolute value of gas-solid energy.

The density profiles in Figure 9 were generated using helium as the probe molecule to determine the local pore volume. The accessible pore spaces for helium and argon are different, because the two molecules have different diameters. On a molecular scale, the location where the solid starts depends on the definition of the dividing surface. In order to compare pore accessibility of helium and argon, we adopted a simple definition for partitioning the pore space from the solid: the point where-gas solid potential energy has a value of zero, a kind of gas-solid collision diameter. This surface of zero potential depends only on the size of the adsorbate molecule and is independent of $\epsilon$ and temperature. Figure 10 shows the number of nodes in the pre-tabulation for which the gas-solid potential is less than zero for helium and argon. E ach node has a volume of $10^{-3} \AA$ in the pre-tabulation. As expected, the number of nodes accessible by the center of an argon molecule is less than the number accessible by helium. The profiles are very similar in shape because there are no side pockets inaccessible to argon. The difference in local pore volumes is due simply to the small difference in molecu- 

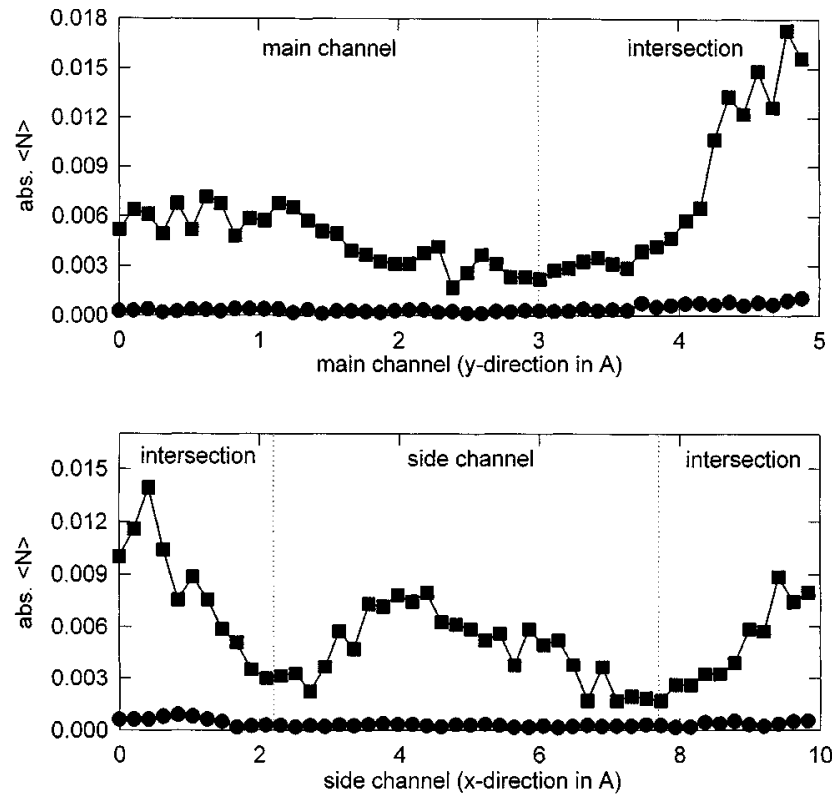

Figure 8. Absolute adsorption of argon and helium in main and side channels of silicalite from GCMC simulations at $305.75 \mathrm{~K}$ and $400 \mathrm{kPa}$.

- : A rgon; $\bullet$ : helium.

lar diameters and has no bearing on excess thermodynamic properties. In fact, this difference is the justification for using a Gibbs dividing surface to convert absolute adsorption variables to experimental excess variables.

\section{Discussion of Results}

Experimental adsorption measurements yield excess variables and molecular simulations yield absolute variables. At the low pressures (a few bars or less) of commercial interest, the absolute adsorption is always larger than the excess adsorption. The difference depends on the reduced temperature of the sorbate molecule, but, for argon on silicalite at ambient temperature, the difference is about $10 \%$. The experimental differential enthalpy $\left(\bar{h}^{m}\right)$ is $4 \%$ higher than the absolute differential enthalpy $\left(\bar{h}^{\text {a }}\right)$ from simulation, even at the limit of zero pressure. Thus, the extraction of meaningful gas-solid potentials requires that the absolute variables of simulation be transformed to the excess variables of experiment.

Conversion of absolute to excess variables requires the helium pore volume of the adsorbent, which in turn requires the helium gas-solid potential function. For silicalite, the well depth for helium gas-silicalite oxygen atom interactions is $\epsilon / \mathrm{K}=28.0 \mathrm{~K}$ and the collision diameter is $2.952 \mathrm{~A}$. A t room temperature, the gas-solid interaction energy is so small compared to the kinetic energy that helium atoms effectively do not adsorb; simulations show that the pore density of helium is within $1 \%$ of its bulk density. A ccording to Eqs. 10 and 11 , the helium pore volume of silicalite is $0.175 \mathrm{~cm}^{3} / \mathrm{g}$, which agrees with the experimental value of $0.173 \mathrm{~cm}^{3} / \mathrm{g}$ from the saturation capacity of silicalite for liquid $n$-hexane (Savitz et al., 1998).
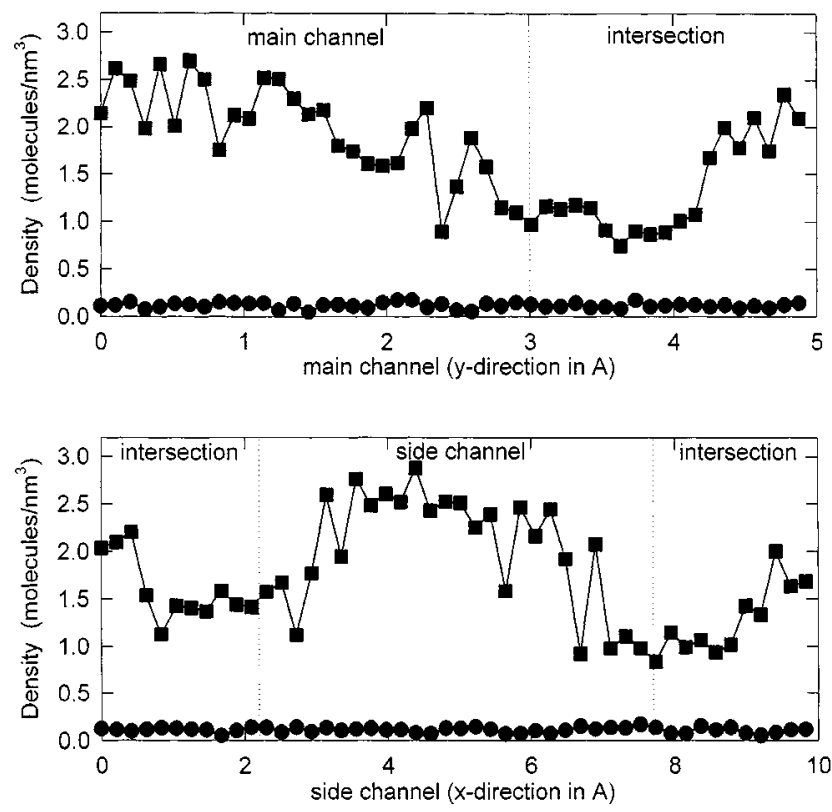

Figure 9. Density of absolute adsorption of argon and helium in main and side channels of silicalite. Legend: same as Figure 8.

The well-depth of the Lennard-J ones $12-6$ potential for interactions of argon molecules with the oxygen atoms of silicalite is $\epsilon / \mathrm{K}=93 \mathrm{~K}$ and the collision diameter is $3.335 \mathrm{~A}$. The potential model assumes pairwise interactions and is based
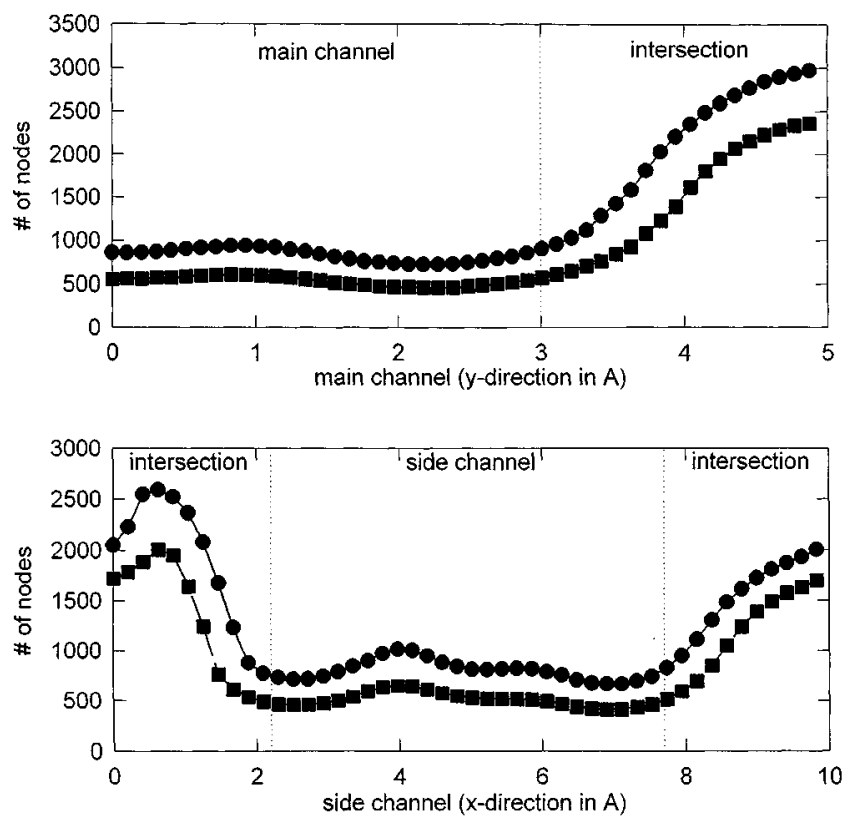

Figure 10. Number of nodes with negative gas-solid potential energy in main and side channels of silicalite for argon and helium.

Helium has more nodes (space) available because of its smaller size. Helium; $\square$ : argon. 
on a detailed atom-atom simulation with the oxygen atoms in 12 unit cells (interactions with silicon atoms are lumped with oxygen atoms). Since silicalite does not contain mobile cations, induction energies are lumped with dispersion. The molecular model agrees with experiment within a few percent at finite loading, at the limit of zero loading, and at different temperatures.

This work demonstrates that the determination of two potential parameters from zero-pressure limits for the Henry constant and the differential enthalpy is extremely sensitive to small experimental errors of the order of a few percent. Beyond the lack of accuracy associated with extracting potential parameters from zero-pressure limits is the existence of solutions which have no physical significance. In general, the robust determination of potential parameters requires experimental data for finite loading, as well as the limit of zero pressure.

\section{Conclusions}

- For adsorption of supercritical gases, absolute simulation variables must be converted to excess variables in order to compare simulations with experimental data. Absolute amount adsorbed is converted to excess amount adsorbed by Eq. 4.

- The helium pore volume is given by its absolute adsorption second virial coefficient, Eqs. 10 and 11. Lennard-J ones potential parameters for helium gas molecules interacting with oxygen atoms of silicalite $(\epsilon / \mathrm{K}=28 \mathrm{~K}$ and $\sigma=2.952 \mathrm{~A})$ predict a pore volume of $0.175 \mathrm{~cm}^{3} / \mathrm{g}$.

- The assumption that helium does not adsorb at low pressure and ambient temperature $(300 \mathrm{~K})$ is justified by the fact that the pore density of helium is equal to its bulk density (within $1 \%$ ) at these conditions.

- Extraction of potential parameters from the Henry constant and limiting differential enthalpy (isosteric heat) at zero pressure is problematic. A robust determination of gas-solid potentials requires additional information such as the amount adsorbed at finite pressure.

\section{Acknowledgment}

Financial support by National Science Foundation Grants CTS9610030 and CTS-0080915 (M yers) and CTS-9725256 (Talu) is gratefully acknowledged.

\section{Notation}

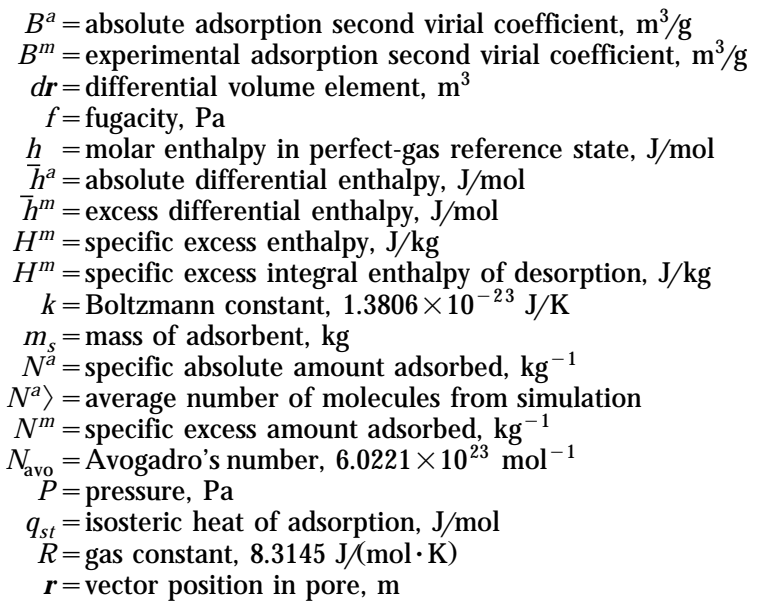

$\mathrm{T}=$ temperature, $\mathrm{K}$

$\mathrm{T}_{0}=$ ambient temperature, $\mathrm{K}$

$\mathrm{V}_{\mathrm{d}}=$ specific dead space volume, $\mathrm{m}^{3} / \mathrm{kg}$

$\mathrm{V}_{\mathrm{p}}=$ specific pore volume, $\mathrm{m}^{3} / \mathrm{kg}$

$\epsilon=$ energy parameter in LJ potential, J

$\rho_{\mathrm{b}}=$ bulk gas density, $\mathrm{m}^{-3}$

$\sigma=$ collision diameter in LJ potential, $\mathrm{m}$

$\phi=$ gas-solid potential energy, J

\section{Literature Cited}

D unne, J. A ., R. M ariwala, M. R ao, S. Sircar, R. J. Gorte, and A. L. $M$ yers, "Calorimetric $\mathrm{H}$ eats of Adsorption and Adsorption I sotherms. 1. $\mathrm{O}_{2}, \mathrm{~N}_{2}, \mathrm{Ar}, \mathrm{CO}_{2}, \mathrm{CH}_{4}, \mathrm{C}_{2} \mathrm{H}_{6}$, and $\mathrm{SF}_{6}$ on Silicalite," L angmuir, 12, 5888 (1996).

Gibbs, J. W., The Scientific Papers of J. William Gibbs, Vol. I, D over Publications, New Y ork, p. 219 (1961).

Golden, T. C., and S. Sircar, "G as A dsorption on Silicalite," J. Colloid Interface Sci., 162, 182 (1994).

Heuchel, M., R. Q. Snurr, and E. Buss, "Adsorption of $\mathrm{CH}_{4}-\mathrm{CF}_{4}$ $M$ ixtures in Silicalite: Simulation, Experiment, and Theory," $L$ angmuir, 13, 6795 (1997).

H irschfelder, J. O., C. F. Curtiss, and R. B. Bird, M olecular Theory of G ases and Liquids, Wiley, New Y ork, p. 1114 (1954).

$\mathrm{Li}, \mathrm{J}$., and $\mathrm{O}$. Talu, "Structural Effect on Molecular Simulations of Tight-Pore Systems," J. Chem. Soc. Faraday Trans., 89, 1683 (1993).

M eier, W. M ., and D. H. O Ison, Atlas of Zeolite Structure Types, Butterworth-H einemann, London, p. 139 (1992).

M etropolis, N., A. W. Rosenbluth, M. N. Rosenbluth, A. H. Teller, and $\mathrm{E}$. Teller, "E quation of State Calculations by $\mathrm{F}$ ast Computing M achines," J. Chem. Phys., 21, 1087 (1953).

M yers, A. L., J. Calles, and G. Calleja, "Comparison of M olecular Simulation of Adsorption with Experiment," Adsorption, 3, 107 (1997).

Nicholson, D., and N. G. Parsonage, Computer Simulations of Statistical Mechanics of Adsorption, A cademic Press, N ew Y ork (1977).

Olson, D. H., G. T. Kokotailo, S. L. Lawton, and W. M. Meier, "Crystal Structure and Structure R elated Properties of ZSM -5," J. Phys. Chem., 85, 2238 (1981).

Savitz, S., F. Siperstein, R. J. Gorte, and A . L. M yers, "Calorimetric Study of Adsorption of Alkanes in High-Silica Zeolites," J. Phys. Chem. B, 102, 6865 (1998).

Sircar, S., "Excess Properties and Thermodynamics of M ulticomponent G as Adsorption," J. Chem. Soc. Faraday Trans. I, 81, 1527 (1985).

Sircar, S., "On the M easurement of G ibbsian Surface E xcess," AIChE J., 47 (2000).

Siperstein, F., R. J. Gorte, and A . L. M yers, "A N ew Calorimeter for Simultaneous $M$ easurements of L oading and $\mathrm{H}$ eats of A dsorption from G as M ixtures," L angmuir, 15, 1570 (1999).

Siperstein, F., and A. L. M yers, "M ixed-G as Adsorption," AIChE J., 47 (2000)

Smit, B., "Simulating the A dsorption I sotherms of M ethane, E thane, and Propane in the Zeolite Silicalite," J. Phys. Chem., 99, 5597 (1995).

Soto, J. L., and A . L. M yers, "M onte Carlo Studies of A dsorption in M olecular Sieves," Mol. Phys., 42, 971 (1981).

Springer, C., C. J. M ajor, and K. Kammermeyer, "L ow Pressure Adsorption of Helium on M icroporous Solids," J. Chem. Eng. Data, 14, 78 (1969).

Stroud, H. J. F., E. Richards, P. Limcharoen, and N. G. Parsonage, "Thermodynamic Study of the Linde Sieve 5A + M ethane System," J. Chem. Soc., Faraday Trans. 1, 72, 942 (1976).

Suzuki, I., K. Kakimoto, and O. Shoichi, "V olume Determination of Adsorption of Helium over some Zeolites with a TemperatureCompensated, Differential Tensimeter having Symmetrical Design," Rev. Sci. Instrum., 58, 1226 (1987).

Talu, O., "Behavior of A romatic Molecules in Silicalite by Direct Integration of Configurational Integral," Molec. Simul., 8, 119 (1991).

Talu, O., "N eeds, Status, Techniques and Problems with Binary G as A dsorption Experiments," Adv. Colloid and Interface Sci., 227, 76 (1998). 